\title{
Article \\ Microstructure and Corrosion Performance of Aluminium Matrix Composites Reinforced with Refractory High-Entropy Alloy Particulates
}

\author{
Elias Ananiadis ${ }^{1}$, Konstantinos T. Argyris ${ }^{1}$, Theodore E. Matikas ${ }^{1, *}$, Athanasios K. Sfikas ${ }^{2}[$ \\ and Alexandros E. Karantzalis ${ }^{1}$ \\ 1 Department of Materials Science and Engineering, University of Ioannina, 45110 Ioannina, Greece; \\ ilias.ananiadis@gmail.com (E.A.); konstantinos.t.argyris@gmail.com (K.T.A.); akarantz@uoi.gr (A.E.K.) \\ 2 Experimental Techniques Centre, Brunel University London, Uxbridge UB8 3PH, UK; thanasfi@gmail.com \\ * Correspondence: matikas@uoi.gr
}

check for updates

Citation: Ananiadis, E.; Argyris, K.T.; Matikas, T.E.; Sfikas, A.K.;

Karantzalis, A.E. Microstructure and Corrosion Performance of Aluminium Matrix Composites Reinforced with Refractory High-Entropy Alloy Particulates. Appl. Sci. 2021, 11, 1300. https:// doi.org/10.3390/app11031300

Received: 8 January 2021

Accepted: 27 January 2021

Published: 1 February 2021

Publisher's Note: MDPI stays neutral with regard to jurisdictional claims in published maps and institutional affiliations.

Copyright: (c) 2021 by the authors. Licensee MDPI, Basel, Switzerland. This article is an open access article distributed under the terms and conditions of the Creative Commons Attribution (CC BY) license (https:// creativecommons.org/licenses/by/ $4.0 /)$.

\begin{abstract}
Novel aluminium matrix composites reinforced by MoTaNbVW refractory high-entropy alloy (HEA) particulates have been fabricated by powder metallurgy. The microstructure of the produced composites has been studied and the corrosion behaviour assessed in $3.5 \% \mathrm{NaCl}$ solution. The composites exhibited low porosity, good homogeneity, few defects, and good distribution of the reinforcing phase in the $\mathrm{Al}$ matrix. No secondary intermetallic phases have been formed while the interface between matrix/reinforcement showed good bonding with no signs of reactivity. Increasing the volume of the reinforcing phase leads to increased hardness values. Al-HEA composites exhibited susceptibility to localised forms of corrosion in $3.5 \% \mathrm{NaCl}$ solution. The microstructure has been analysed and corrosion mechanisms have been formulated.
\end{abstract}

Keywords: aluminium matrix composites; particulate reinforcement; high-entropy alloys; MoTaNbVW; corrosion; potentiodynamic polarisation

\section{Introduction}

Metal matrix composites (MMCs) consist of a metallic matrix with a ceramic or a metallic reinforcement. MMCs exhibit improved properties such as high specific strength, high modulus, high hardness, and improved tribological properties. MMCs have been replacing monolithic alloys in various applications in aerospace, transportation, and other sectors [1-5]. A variety of MMCs has been developed with different matrices such as aluminium, copper, and stainless steel. Aluminium matrix composites (AMCs) reinforced with various particulates including $\mathrm{Al}_{2} \mathrm{O}_{3}$ [6-9], $\mathrm{SiC}$ [10-13], $\mathrm{TiC}$ [14-16], and $\mathrm{B}_{4} \mathrm{C}$ [17-20] have been studied.

Several studies on the electrochemical properties of AMCs reinforced with various ceramic reinforcements, including $\mathrm{Al}_{2} \mathrm{O}_{3} / \mathrm{SiC}$ [21], $\mathrm{B}_{4} \mathrm{C}$ [17], $\mathrm{SiC}$ [10,11], and $\mathrm{AlN}$ [22], indicate that the composites exhibit decreased corrosion resistance compared to the monolithic alloy. This is attributed to the breakdown of the continuous passive film on matrixreinforcement interface [23], the formation of galvanic couples between $\mathrm{Al}$ and reinforcement $[17,24]$, the formation of voids at matrix-reinforcements interfaces [25], interfacial layers around the reinforcement that may promote the galvanic effect [26], and increase in the dislocation density around particles clusters [27]. Another possible explanation for the decreased corrosion resistance of Al-based composites compared to the monolithic alloys is the pitting corrosion at the interfaces between the reinforcing particulates, secondary precipitates, and the reduction of oxygen on cathodic particles and precipitates [28]. On the other hand, several studies indicate that the introduction of the reinforcement in the Al matrix leads to improved corrosion performance [12,13,29,30]. Various interpretations may explain the improved corrosion performance, including the formation of reaction 
products that may act as barriers, interrupting the continuity of the matrix channels within the matrix [12], and matrix/reinforcement decoupling [29]. In other research efforts, AMCs exhibited comparable corrosion resistance with the monolithic alloy $[14,15]$. The effect of the reinforcement on the corrosion performance of AMCs may vary and depends on the environmental conditions and processing route [31]. Furthermore, other factors that may modify corrosion behaviour include primary interfacial reaction products between matrix/reinforcement [32], secondary precipitates in the as-cast states $[33,34]$ and heat-treated states [34], aging kinetics [35], and electrolyte type [36].

High-entropy alloys (HEAs) have attracted a lot of attention. A high-entropy alloy contains at least five principal elements with concentrations of each element from 5 to 35 at. $\%$, with exceptional physical and anti-corrosive properties deriving from four core effects: (a) high entropy, (b) sluggish diffusion, (c) severe lattice distortion, and (d) cocktail effect [37,38].

Due to their sluggish diffusion behaviour, less reactive nature, and attractive properties, HEAs are an outstanding choice for reinforcement in AMCs $[39,40]$. Various researchers studied these novel MMCs reinforced with HEA particulates using different types of matrixes, HEA reinforcement, and manufacturing routes [4,40-46]. Al-5083 matrix composites reinforced with $\mathrm{CoCrFeNi}$ and $\mathrm{AlCoCrFeNi} \mathrm{HEAs}$, have been fabricated by additive manufacturing and submerged friction stir processing, respectively $[39,40]$. The produced composites exhibited improved tensile properties, compressive strength, ultimate tensile strength, yield strength compared to the monolithic alloys. AlCoCrFeNi HEA, in equiatomic and non-equiatomic compositions, has been employed as the reinforcement in spark plasma sintered AMCs. The fabricated composites exhibited improved yield strength, high strength, increased fracture surface energy, but low plasticity [41,42]. Composites based on Al-7075 and commercially pure $\mathrm{Al}$ have been fabricated with the addition of AlCoCrFeNiTi HEA particulates (equiatomic and non-equiatomic). The produced composites manifested improved strength, plasticity, and extreme improvement in ultimate tensile strength compared to the monolithic alloys [43,44]. Al-based composites reinforced by various HEA particulates exhibited improved hardness, Young modulus, and strength compared to conventional $\mathrm{Al}$ alloys $[4,45,46]$.

The aim of the current investigation is to evaluate the feasibility of fabricating novel AMCs reinforced by MoTaNbVW refractory HEA particulates via a powder metallurgy route. Furthermore, to study the microstructure and the corrosion behaviour of the composites in $3.5 \mathrm{wt} . \% \mathrm{NaCl}$ solution. To the best of the authors' knowledge, this is the first effort to fabricate and study Al-based composites with the employment of refractory HEA particulates. Furthermore, works on the corrosion behaviour of AMCs reinforced by HEA particulates are extremely limited [47]. It should be mentioned that this is a preliminary study and part of a larger effort to study different AMCs reinforced by various HEA particulates with different reinforcement volumes. The final goal is to develop AMCs with improved mechanical, corrosion, and tribological properties, while at the same time, maintain high ductility and keep production costs low.

\section{Materials and Methods}

\subsection{Fabrication}

MoTaNbVW reinforcement has been produced by vacuum arc melting. Details on the fabrication route and attained microstructures can be found elsewhere [48-51]. Afterwards, HEA samples were crushed into fine particles using a planetary mill (Fritsch Pulverisette 7 Premium Line, Idar-Oberstein, Germany). The samples were ground in a bowl with a capacity of $20 \mathrm{~mL}$ and 10 grinding balls with $10 \mathrm{~mm}$ diameter, the grinding time was $10 \mathrm{~min}$ at $850 \mathrm{rpm}$. The process took place in intervals of $20 \mathrm{~s}$ grinding and $80 \mathrm{~s}$ of pausing to prevent the samples from overheating. The achieved fineness of the HEA powder was approximately $40 \mu \mathrm{m}$. Commercial aluminium AA-1050 powder (purity $99.5 \%$ ) was used as the matrix and the equiatomic refractory high entropy alloy MoTaNbVW as the reinforcement in order to produce composites of various compositions $(0,1,3$, and $5 \mathrm{vol} \%$ reinforcement). A powder metallurgy route was followed as the fabrication technique. 
For each configuration, the powder of $\mathrm{Al}$ and HEA were weighted and stirred into a beaker with methanol to avoid agglomeration and left to dry into a hot plate stirrer. The final powders for the monolithic alloy and Al-HEA composites were compacted into a cylindrical pellet of $14 \mathrm{~mm}$ in diameter using a hydraulic press at 7.6 tons of force. Each specimen had a weight of approximately $5 \mathrm{~g}$. Due to the variation of volume and density of the reinforcement, the height of each pellet ranged from $12 \mathrm{~mm}$ for the monolithic alloy to $11.2 \mathrm{~mm}$ for the $5 \mathrm{vol} \%$ composition. Then, the pellets were carried into a steel die with a diameter of $15.3 \mathrm{~mm}$ (slightly bigger from the cold press specimens to avoid a breakdown during the insertion), covered with graphite powder for lubrication, and sintered into a hot press furnace (manufactured by Termolab, Agueda, Portugal). The final height for specimens ranged from $10.2 \mathrm{~mm}$ for the monolithic alloy to $9.2 \mathrm{~mm}$ for the $5 \mathrm{vol} \%$ composition. Sintering was executed in three steps. Initially, the temperature was increasing at a rate of $50{ }^{\circ} \mathrm{C} / \mathrm{min}$ until it was stabilised at $550{ }^{\circ} \mathrm{C}$ under vacuum conditions. Afterwards, after $1 \mathrm{~h}$, the loading process began gradually at a rate of $1000 \mathrm{~N} / \mathrm{min}$ until the press obtained the desired load of $6500 \mathrm{~N}$. The load was applied to the specimens for $30 \mathrm{~min}$. Then, the specimens were left to cool in the furnace.

Afterwards, specimens have been subject to standards metallographic procedures for further analysis. More specifically, each specimen was cleaned after extraction from the die to remove impurities. The surface of the samples was ground with $\mathrm{SiC}$ sandpapers with final grit of 1200 . Polishing was carried on with the use of a fine polishing cloth and diamond spray of 1 micron. After polishing, each specimen was rinsed with ethanol to remove contamination. The final outcome was a mirror-polished surface.

\subsection{X-ray Diffraction and Hardness Testing}

The phase identification of the composites was performed by a Bruker D-8 Advance Diffractometer (Bruker, Billerica, MA, USA), Cu K-alpha radiation. An Innovatest IN-700M (Innovatest, Europe BV, Maastricht, Netherlands) tester was employed to perform the hardness testing (average of five measurements per sample, two samples per configuration).

\subsection{Scanning Electron Microscopy}

The microstructure of the produced materials was studied with a Zeiss Supra 35VP (Carl Zeiss Microscopy, Jena, Germany) field emission gun scanning electron microscope and an LEO 1455VP (Carl Zeiss Microscopy, Jena, Germany) scanning electron microscope. Both were equipped with EDAX EDX detectors (Ametek, Berwyn, PA, USA). After potentiodynamic polarisation, the surface of $\mathrm{Al}$ and the composites were studied by scanning electron microscopy.

\subsection{Corrosion Testing}

Potentiodynamic polarisation testing was performed by a Gamry Reference 600 (Gamry Instruments, Warminster, PA, USA) potentiostat/galvanostat with the employment of a standard three-electrode cell (saturated calomel as the reference electrode (SCE) and a graphite gauge used as the counter electrode). Corrosion behaviour was studied in aerated $3.5 \% \mathrm{NaCl}$ solution ( $\mathrm{pH} 7$ ). Open-circuit potential (Eocp) was determined after $1 \mathrm{~h}$ of immersion in the solution. The scan rate for the polarisation testing was $10 \mathrm{mV} / \mathrm{min}$. Four measurements were performed for each composition.

\section{Results and Discussion}

\subsection{Microstructural Analysis-Hardness}

Figure 1 presents a panoramic view of the HEA particulates after the milling process, through SEM examination. It also presents the mean actual composition of the powder particles in at.\% after energy dispersive X-ray spectroscopy (EDS) analysis at various particle areas. It can be observed that most of the particles show an angular morphology. The first estimation of their size shows that it lays within the range of $1 \mu \mathrm{m}$ to $30 \mu \mathrm{m}$. 

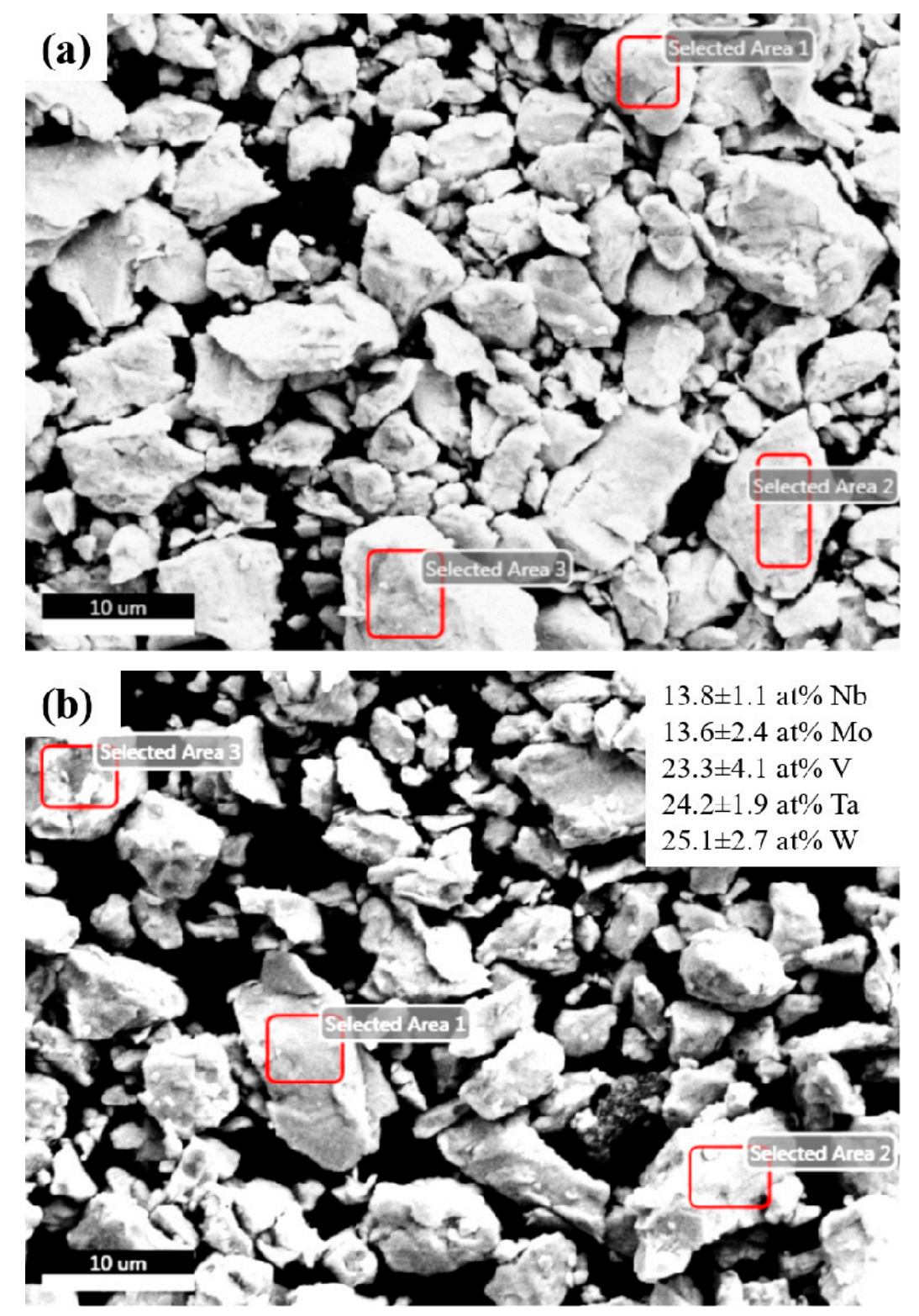

Figure 1. Microstructure and composition (average of six different measurements) of MoTaNbVW powder under SEM (Secondary electron mode). (a,b) represent two different areas where point analysis has been performed in 6 points in total.

Figure 2 presents the $\mathrm{X}$-ray diffractograms for the different materials produced in the present effort. It can be seen that in all cases, two different phases can be distinguished-an FCC phase of the higher intensities that dominates, corresponding to $\mathrm{Al}$, and a $\mathrm{BCC}$ phase of significantly lower peak intensities that corresponds to the HEA-reinforcing particles. These significantly lower peak intensities of the reinforcing phase particles are expected since their overall content is relatively small (up to $5 \mathrm{vol} . \%$ ). MoTaNbVW produced in the form of bulk material consists of two BCC solid solutions- one rich in MoTaW and one rich in $\mathrm{NbV}$. This is the result of a low-extend segregation of these two phases during the solidification process. It is well understood that the segregation of phases is inevitable, and it is acceptable as long as these phases are solid solutions rather than brittle intermetallic phases. It should be mentioned that MoTaNbVW was one of the pioneering refractory HEAs that has been developed and it meets the prerequisites of simple solid solutions formation. A thorough evaluation of the microstructure of MoTaNbVW can be found in previous efforts $[50,51]$. 


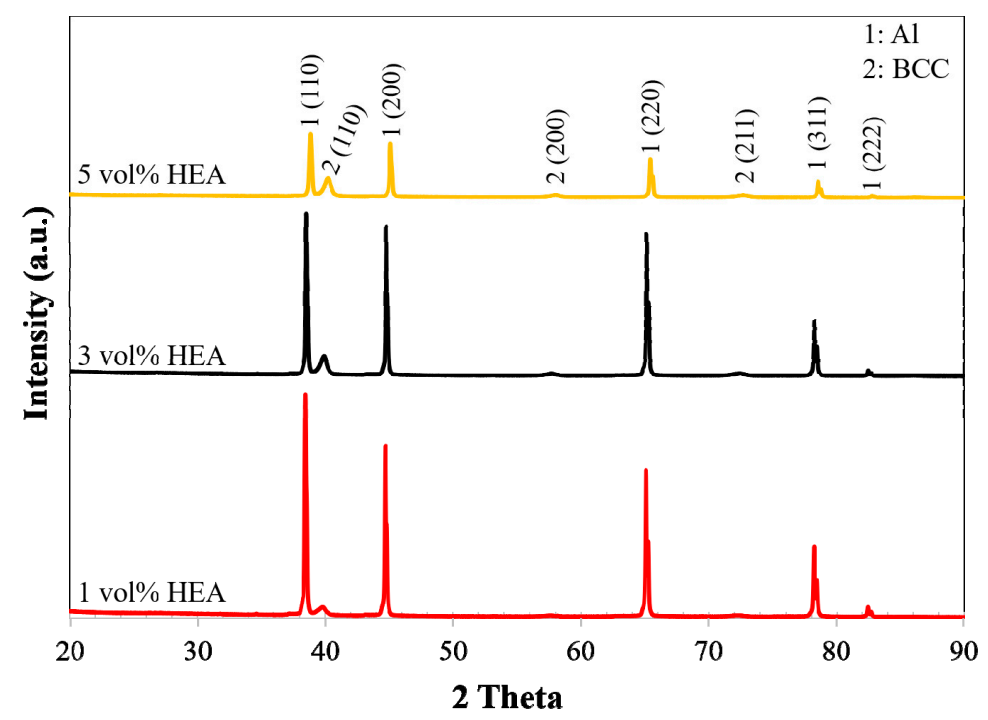

Figure 2. X-ray diffractograms of Al-HEA composites.

The particle distribution within the $\mathrm{Al}$ matrix for all the different composite systems is shown in Figure 3. As a first observation, it can be noticed that the actual particle content is in agreement with the nominal compositions: the higher the nominal composition, the more increased the actual reinforcing particle content. This observation refers to all the different particle sizes—as the particle content increases, the number of both the bulk and the sub-micron particles increases. As far as the particle distribution is concerned, it can be observed from Figure 3 that the distribution appears to be almost homogeneous for all the different particle sizes. Such a homogeneous distribution is expected since powder metallurgy processing route, due to the primary powder mixing process, ensures this type of microstructural homogeneity at the final sintered products. Another important observation that rises from Figure 3 is related to the quality of the actual sintering process. It can be noticed that in all cases there is no significant evidence of pores or other defects (flaws, micro-cracks, micro-voids) which implies that the sintering process was fully developed and concluded, leading to fully dense and rigid composite systems.
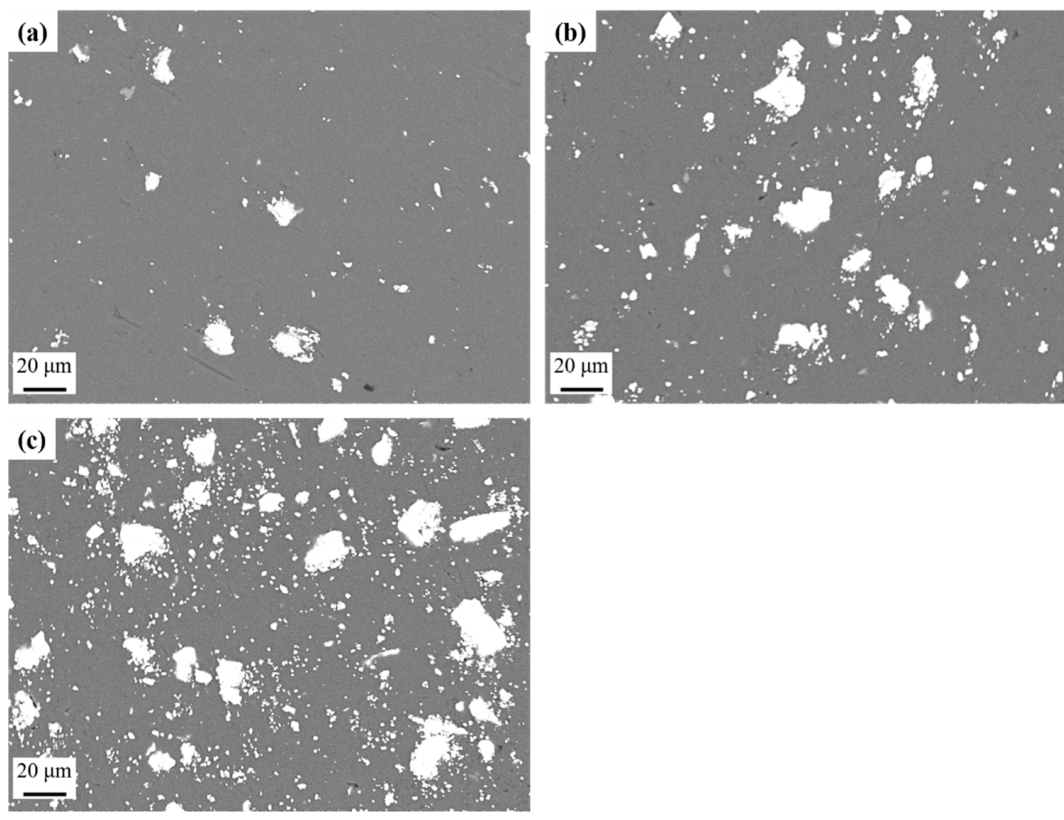

Figure 3. Microstructure of the produced composites (Back scattered electron mode): (a) Al-1 vol\% HEA, (b) Al-3 vol\% HEA, and (c) Al-5 vol\% HEA. 
Figure 4 illustrates an EDS mapping on a selected region around a bulk reinforcing particle in order to reveal the elemental distribution. It can be observed that the reinforcing particle consists of the elements related to the refractory HEA system adopted in the present effort. Figure 4 also reveals useful information on the nature and integrity of the matrix-reinforcement interfacial area. Indeed, no signs of pores or interfacial detachment can be observed. Additionally, there is no significant evidence- at least at the observed magnification of severe reactivity between the $\mathrm{Al}$ matrix and the HEA system elements at the interfacial areas. This observation is very important because it indicates a lack of potential brittle intermetallic phase formation. The presence of intermetallic phases at the interfacial area would cause deteriorating effects on the properties of final composite systems [52]. EDX analysis revealed no significant traces of oxide phases (especially associated with Al). This may be attributed to the use of elemental Al powder that was protected in the supply container and used at the very last moment of the overall process. This handling reduced the exposure time to the atmosphere that could result in potential oxygen absorption. Furthermore, graphite powder was employed as a lubricant during the mechanical processing stage. The presence of graphite creates a reduction atmosphere at the following stage of hot pressing, ensuring intensive oxygen removal from the powders. The hot-pressing stage was performed under vacuum reducing further the potential for oxygen contamination.
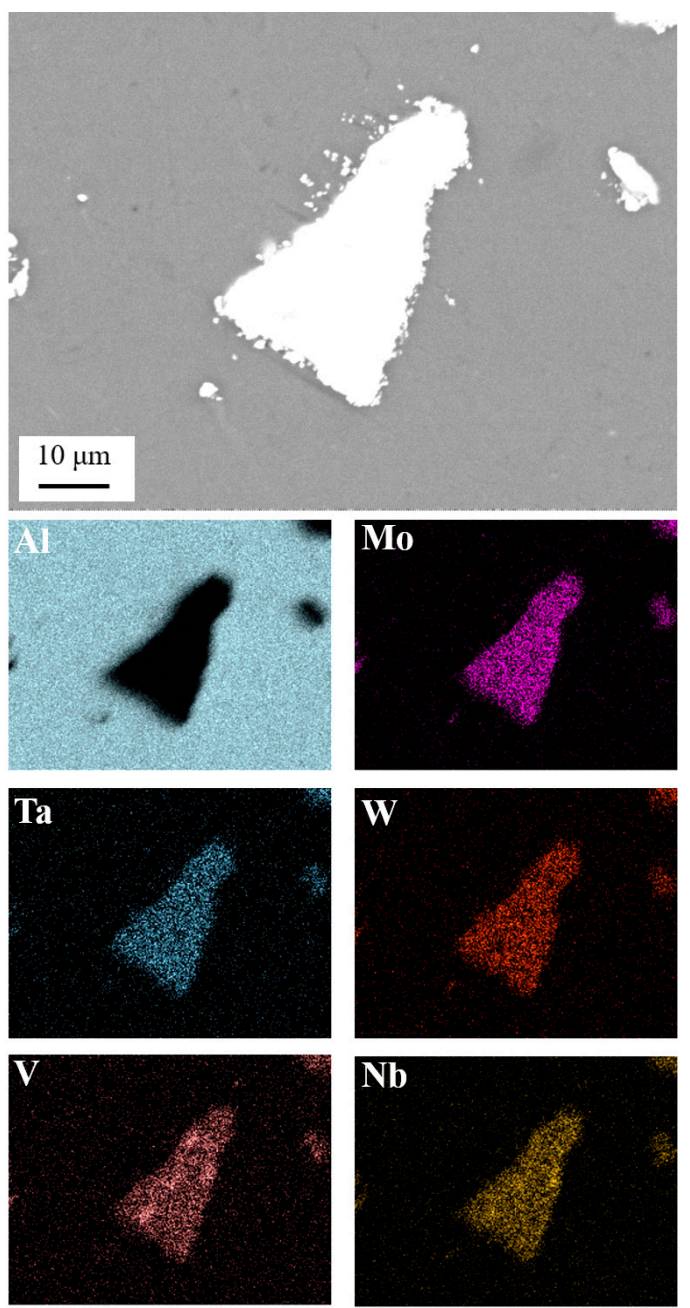

Figure 4. Microstructure and elemental map of MoTaNbVW particulate in higher magnification (BE mode). 
Figure 5 presents the hardness measurements for the different systems produced in the present effort. The increase of the HEA particle content results in an increase of the overall composite hardness, indicating the reinforcing action of the hard and strong HEA phase. It should be noticed here that the selected HEA system possesses a hardness of $97 \pm 4$ HRB (Rockwell B) [50]. Another interesting observation is the consistency of the values and the deviation of hardness measurements. This may be explained by the good microstructural homogeneity and the good particle distribution of the reinforcement in the matrix.

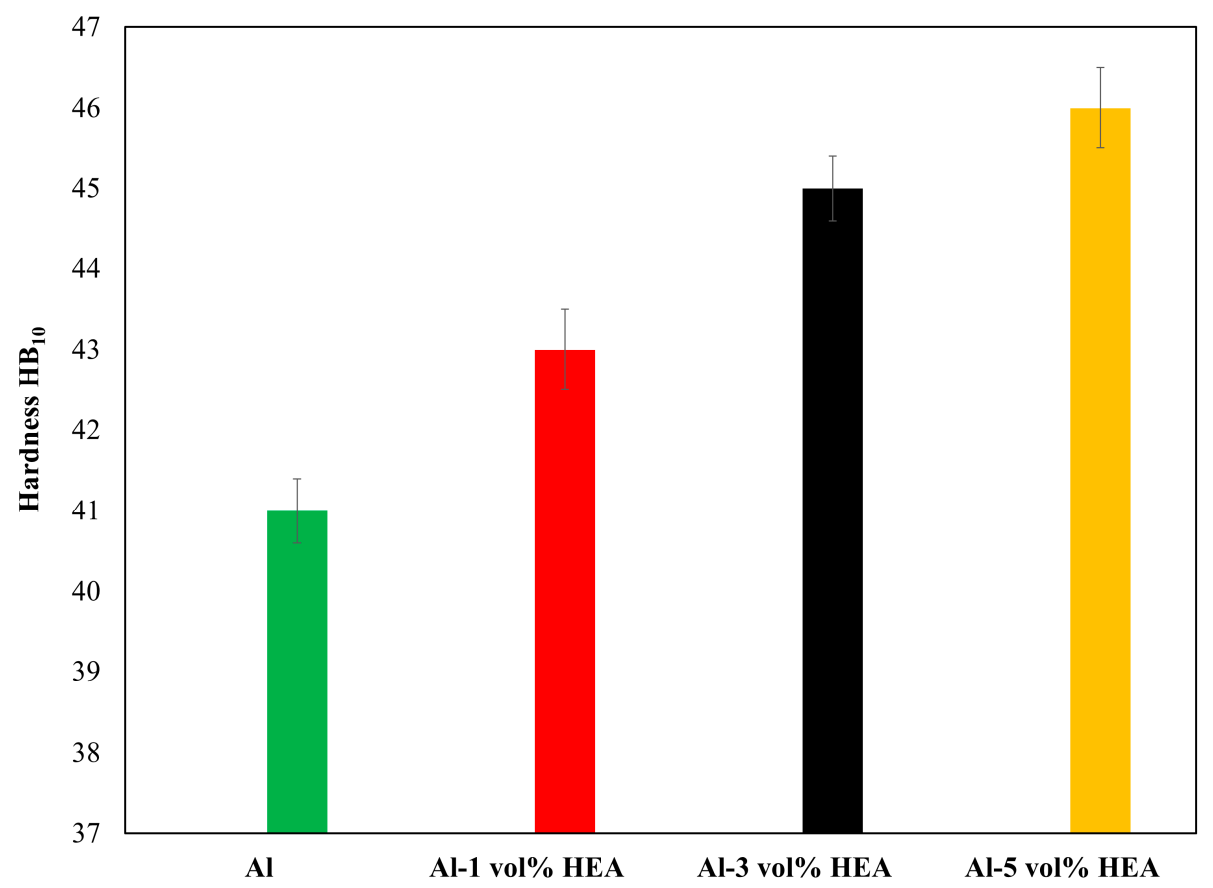

Figure 5. Hardness values for monolithic $\mathrm{Al}$ and $\mathrm{Al}-\mathrm{HEA}$ composites.

\subsection{Corrosion Performance}

Figure 6 illustrates the potentiodynamic polarisation curves for monolithic $\mathrm{Al}$ and the produced composites in aerated $3.5 \% \mathrm{NaCl}$ solution ( $\mathrm{pH} 7$ ). Polarisation curves for the composites with the lower HEA particulate content appear to be similar to the polarisation curve of Al. However, $\mathrm{Al}-5 \mathrm{vol} \% \mathrm{HEA}$ exhibits somewhat different polarisation behaviour. More specifically, corrosion potential (Ecorr) appear to be slightly increased while the cathodic current densities correspond to higher values compared to $\mathrm{Al}$ and lower HEA containing composites. The increased cathodic current density values can be explained by the increased volume of the cathodic HEA particulates [15]. Nonetheless, the curves exhibit typical polarisation behaviour for $\mathrm{Al}$ and $\mathrm{Al}$ alloys in $\mathrm{NaCl}$ solutions; pitting potentials (Epit) are a few decades of $\mathrm{mV}$ higher than the corrosion potentials (Ecorr). The anodic part of the polarisation curves is divided into areas with a decreased rate of current density increase and areas with a sustained flat gradient; in the sustained flat gradient current density increases by several orders of magnitude, an indication of susceptibility to localised forms of corrosion [52-54]. It is thus concluded that the corrosion behaviour of the composites in $3.5 \% \mathrm{NaCl}$ solution appears to be mainly controlled by the corrosion of matrix, in agreement with other studies $[14,28]$. 


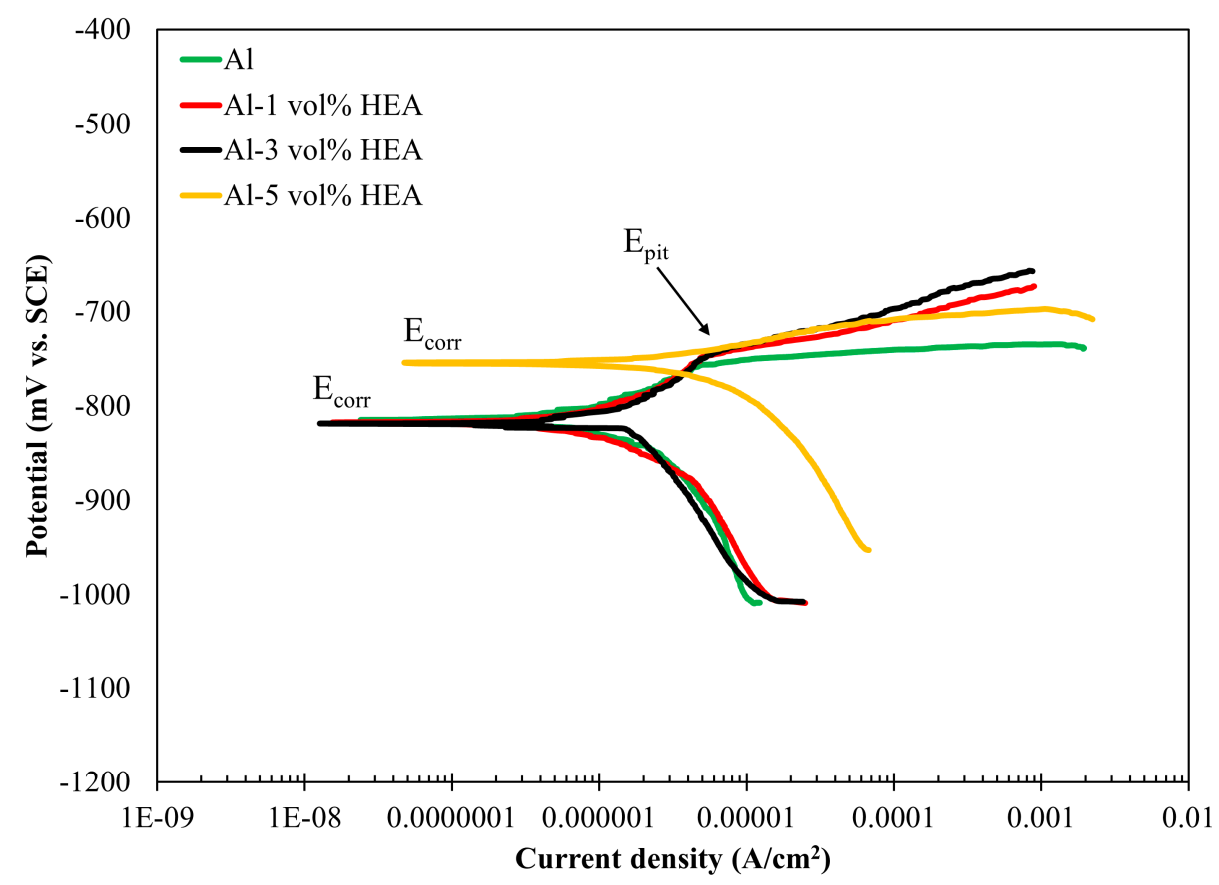

Figure 6. Potentiodynamic polarisation curves for $\mathrm{Al}$ and Al-HEA composites in aerated 3.5\% $\mathrm{NaCl}$ solution.

Figure 7 presents the surface of the monolithic alloy and the composites under SEM after potentiodynamic polarisation in $3.5 \% \mathrm{NaCl}$ solution. The surface appears to be degraded with the formation of pits. A most interesting observation is that $\mathrm{Al}$ on the matrixreinforcement interface (Figure $7 \mathrm{~b}-\mathrm{d}$ ) appears to be subject to preferential dissolution. This can be attributed to the high nobility of the reinforcing phase compared to the Al matrix. The galvanic effect between the matrix and the reinforcement can be further postulated by the presence of high amounts of oxygen on areas of the matrix close to the reinforcement (Figure 7e). It should be mentioned that the reinforcement appears to be free of any corrosion signs. The main corrosion mechanism of MoTaNbVW in $3.5 \% \mathrm{NaCl}$ solution is uniform corrosion and intergranular corrosion of inter-dendrites at the dendritic/interdendritic boundaries due to the electrochemical potential difference between the dendrites (rich in $\mathrm{Mo}, \mathrm{Ta}, \mathrm{W}$ ) and inter-dendrites (rich in $\mathrm{Nb}, \mathrm{V}$ ). $\mathrm{Mo}, \mathrm{W}$, and $\mathrm{Nb}$ are beneficial in decreasing the occurrence of pit corrosion in the MoTaNbVW system [55].

Corrosion behaviour of the composites appears to be the sum of counterbalancing mechanisms: HEA particulates may improve corrosion performance of the composites by stabilising the oxide film. Indeed, Wang et al. reported that the introduction of $\mathrm{CuZr}$ NiAlTiW HEA particulates in Al led to improved corrosion performance due to the stabilising effect of $\mathrm{Ni}$ and $\mathrm{W}$ in the transition layer [47]. In addition, the introduction of HEA particulates in $\mathrm{Al}$ leads to a decrease of the available $\mathrm{Al}$ area that may be subject to degradation. On the other hand, the introduction of HEA particulates might lead to the formation of discontinuities on the $\mathrm{Al}$ oxide film; the interface of $\mathrm{Al} /$ reinforcement may act as a corrosion initiation site. Increasing the volume of the reinforcement might lead to a more pronounced galvanic effect that may accelerate the dissolution of $\mathrm{Al}$ on the $\mathrm{Al} /$ reinforcement interface. Another consideration is the galvanic effect between areas richer in HEA particulates and areas with a lower concentration of particulates. However, the intensity of the galvanic effect might be lessened by the good homogeneity/particle distribution and the lack of formation of secondary intermetallic phases or layers with different compositions. Other studies highlighted the importance of the high sintering quality and relative density on enhancing the corrosion resistance of AMCs reinforced by HEA particulates in a seawater solution [47]. 

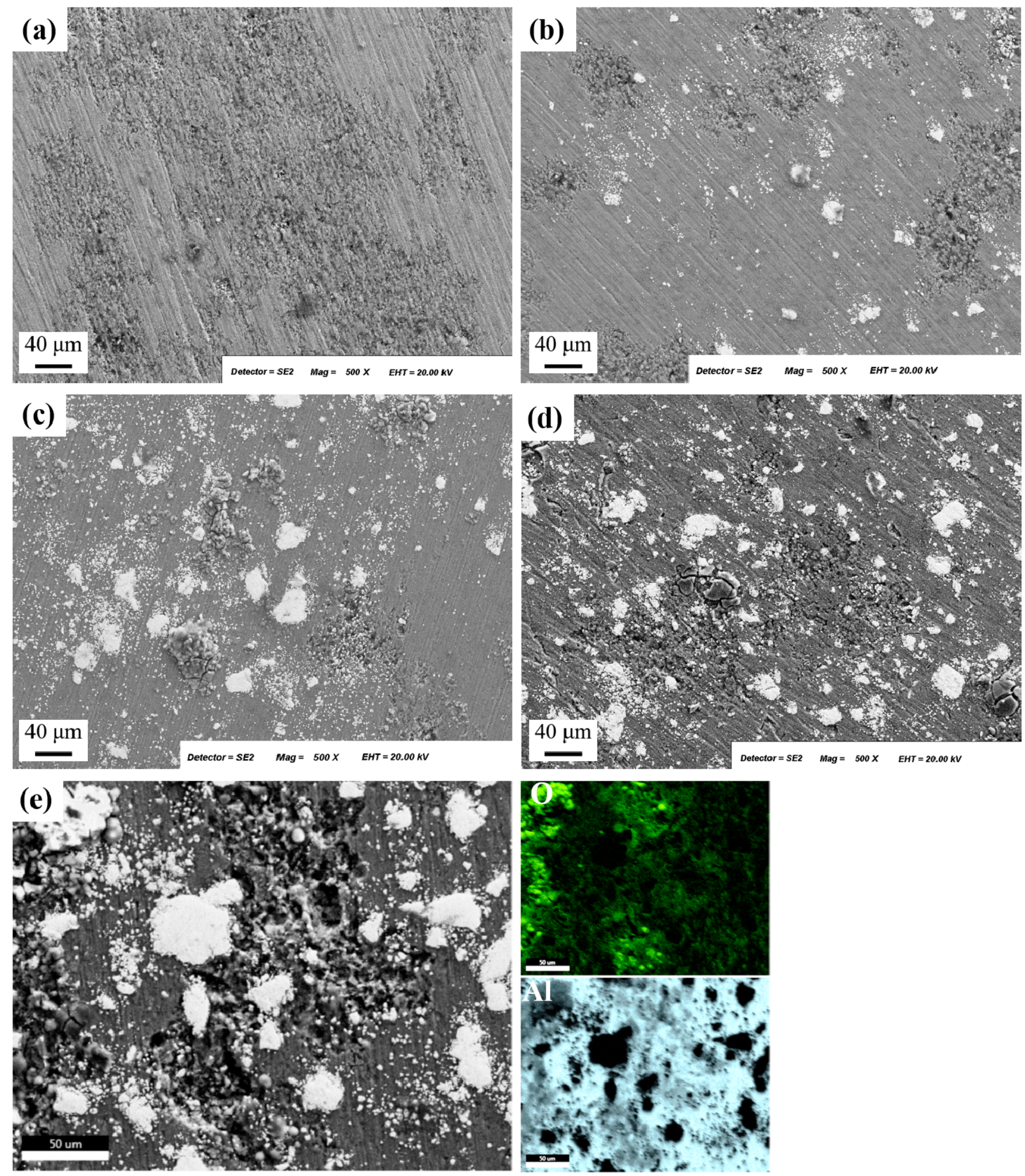

Figure 7. Microstructure of the corroded surface (SE mode) after polarisation in aerated $3.5 \% \mathrm{NaCl}$ solution: (a) $\mathrm{Al}$, (b) $\mathrm{Al}-1$ vol\% HEA, (c) Al-3 vol\% HEA, and (d,e) Al-5 vol\% HEA with elemental map. 


\title{
4. Conclusions
}

- Novel aluminium matrix composites reinforced by MoTaNbVW refractory highentropy alloy particulates have been successfully produced by powder metallurgy.

- The microstructure of the produced AMCs appears to be homogenous, with low porosity, few defects, and good distribution of the reinforcing phase in the Al matrix.

- No secondary intermetallic phases have been formed while the interface between matrix and reinforcement showed good bonding without any signs of reactivity.

- Increasing the volume of the reinforcing phase leads to increased hardness values.

- Al-HEA composites exhibited typical polarization behaviour for $\mathrm{Al}$ and $\mathrm{Al}$ alloys in $\mathrm{NaCl}$ solutions. All examined materials were susceptible to localised forms of corrosion in $3.5 \% \mathrm{NaCl}$ solution, while aluminium matrix on the reinforcement/matrix interface has been subject to selective dissolution. The corrosion behaviour of the produced composites appears to be mainly controlled by the corrosion of the matrix.

\begin{abstract}
Author Contributions: Conceptualisation, E.A. and T.E.M.; methodology, E.A., T.E.M., A.K.S., and A.E.K.; software, E.A.; validation, E.A., T.E.M., and A.E.K.; formal analysis, E.A., K.T.A., and A.K.S.; investigation, E.A., K.T.A., and A.K.S.; resources, T.E.M.; data curation, E.A.; writing-original draft preparation, E.A., K.T.A., A.K.S., and A.E.K.; writing-review and editing, T.E.M. and A.E.K.; visualisation, E.A. and A.K.S.; supervision, T.E.M.; project administration, T.E.M.; funding acquisition, T.E.M. All authors have read and agreed to the published version of the manuscript.
\end{abstract}

Funding: This research received no external funding.

Institutional Review Board Statement: Not applicable.

Informed Consent Statement: Not applicable.

Data Availability Statement: The data presented in this manuscript are available upon request.

Conflicts of Interest: The authors declare no conflict of interest.

\section{References}

1. Surappa, M.K. Aluminium matrix composites: Challenges and opportunities. Sadhana 2003, 28, 319-334. [CrossRef]

2. Wlodarczyk-Fligier, A.; Dobrzanski, L.A.; Adamiak, M. Influence of heat treatment on properties and corrosion resistance of Al-composite. J. Achiev. Mater. Manuf. Eng. 2007, 21, 55-58.

3. Mattern, A.; Huchler, B.; Staudenecker, D.; Oberacker, R.; Nagel, A.; Hofmann, M.J. Preparation of interpenetrating ceramic-metal composites. J. Eur. Ceram. Soc. 2004, 24, 3399-3408. [CrossRef]

4. Prabakaran, R.K.; Sait, A.N.; Sentilkumar, V. Synthesis and Characteristization of High Entropy Alloy (CrMnFeNiCu) Reinforced AA6061 Aluminium Matrix Composite. J. Mech. Mechan. Eng. 2017, 21, 415-424.

5. Miracle, D.B.; Donaldson, S.L. Handbook ASM; ASM International: Materials Park, OH, USA, 2001; pp. 27-34.

6. El-Aziz, K.A.; Saber, D.; Sallam, H.E.-D.M. Wear and Corrosion Behavior of Al-Si Matrix Composite Reinforced with Alumina. J. Bio. Tribo. Corros. 2015, 1, 5. [CrossRef]

7. Kang, Y.C.; Chan, S.L.I. Tensile properties of nanometric $\mathrm{Al}_{2} \mathrm{O}_{3}$ particulate-reinforced aluminum matrix composites. Mater. Chem. Phys. 2004, 85, 438-443. [CrossRef]

8. Mazahery, A.; Ostadshabani, M. Investigation on mechanical properties of nano- $\mathrm{Al}_{2} \mathrm{O}_{3}$-reinforced aluminum matrix composites. J. Comp. Mat. 2011, 45, 2579-2586. [CrossRef]

9. Hesabi, Z.R.; Simchi, A.; Reihani, S.M.S. Structural evolution during mechanical milling of nanometric and micrometric $\mathrm{Al}_{2} \mathrm{O}_{3}$ reinforced Al matrix composites. Mater. Sci. Eng. A 2006, 428, 159-168. [CrossRef]

10. Gurrappa, I.; Bhanu Prasad, V.V. Corrosion characteristics of aluminium based metal matrix composites. Mater. Sci. Tech. 2006, 22, 115-122. [CrossRef]

11. Cheng, Y.L.; Chen, Z.H.; Wu, H.L.; Wang, H.M. The Corrosion Behaviour of the Aluminum Alloy 7075/SiCp Metal Matrix Composite Prepared by Spray Deposition. Mater. Corros. 2007, 58, 280-284. [CrossRef]

12. Candan, S.; Bilgic, E. Corrosion Behavior of Al-60 vol.\% SiCp Composites in NaCl Solution. Mater. Lett. 2004, 58, 2787-2790. [CrossRef]

13. Zakaria, H.M. Microstructural and corrosion behavior of $\mathrm{Al} / \mathrm{SiC}$ metal matrix composites. Ain Shams Eng. J. 2014, 5, 831-838. [CrossRef]

14. Lekatou, A.G.; Poulia, A.; Mavros, H.; Karantzalis, A.E. Thermal Treatment, Sliding Wear and Saline Corrosion of Al In Situ Reinforced with $\mathrm{Mg}_{2} \mathrm{Si}$ and Ex Situ Reinforced with TiC Particles. J. Mater. Eng. Perform. 2018, 27, 5030-5039. [CrossRef]

15. Lekatou, A.; Karantzalis, A.E.; Evangelou, A.; Gousia, V.; Kaptay, G.; Gácsi, Z.; Baumli, P.; Simon, A. Aluminium reinforced by WC and TiC nanoparticles (ex-situ) and aluminide particles (in-situ): Microstructure, wear and corrosion behaviour. Mater. Des. 2015, 65, 1121-1135. [CrossRef] 
16. Dikici, B.; Bedir, F.; Gavgali, M. The effect of high TiC particle content on the tensile cracking and corrosion behavior of Al-5Cu matrix composites. J. Comp. Mater. 2020, 54, 1681-1690. [CrossRef]

17. Han, Y.M.; Chen, X.G. Electrochemical Behavior of $\mathrm{Al}-\mathrm{B}_{4} \mathrm{C}$ Metal Matrix Composites in NaCl Solution. Materials 2015, 32, 6455-6470. [CrossRef]

18. Kalaiselvan, K.; Murugan, N.; Parameswaran, S. Production and characterization of AA6061-B 4 C stir cast composite. Mater. Des. 2011, 32, 4004-4009. [CrossRef]

19. Topcu, I.; Gulsoy, H.O.; Kadioglu, N.; Gulluoglu, A.N. Processing and mechanical properties of $\mathrm{B}_{4} \mathrm{C}$ reinforced $\mathrm{Al}$ matrix composites. J. Alloy Compd. 2009, 482, 516-521. [CrossRef]

20. Nie, C.; Gu, J.; Liu, J.; Zhang, D. nvestigation on microstructures and interface character of $\mathrm{B}_{4} \mathrm{C}$ particles reinforced $2024 \mathrm{Al}$ matrix composites fabricated by mechanical alloying. J. Alloy Compd. 2008, 454, 118-122. [CrossRef]

21. Nunes, P.C.R.; Ramanathan, L.V. Corrosion Behavior of Alumina-Aluminum and Silicon Carbide-Aluminum Metal-Matrix Composites. Corrosion 1995, 51, 610-617. [CrossRef]

22. Liu, Z.S.; Wu, B.T.; Gu, M.Y. Effect of AlN Particles on the Corrosion Behavior of Al/AlNp Composites. J. Mater. Sci. 2007, 42, 5736-5741. [CrossRef]

23. Nath, D.; Namboodhiri, T.K.G. Some corrosion characteristics of aluminium-mica particulate composites. Corros. Sci. 1989, 23, 1215-1221, 1223-1229. [CrossRef]

24. Hihara, L.H.; Latanision, R.M. Galvanic Corrosion of Aluminum-Matrix Composites. Corrosion 1992, 48, 546-552. [CrossRef]

25. Trowsdale, A.G.; Noble, B.; Harris, S.J.; Gibbins, I.S.R.; Thompson, G.E.; Wood, G.C. The influence of silicon carbide reinforcement on the pitting behaviour of aluminium. Corros. Sci. 1996, 38, 177-191. [CrossRef]

26. De Salazar, J.M.G.; Urena, A.; Manzanedo, S.; Barrena, M.I. Corrosion behaviour of $\mathrm{AA}_{6061}$ and $\mathrm{AA} 7005$ reinforced with $\mathrm{Al}_{2} \mathrm{O}_{3}$ particles in aerated 3.5\% chloride solutions: Potentiodynamic measurements and microstructure evaluation. Corros. Sci. 1988, 41, 529-545. [CrossRef]

27. Paciej, R.C.; Agarwala, V.S. Influence of Processing Variables on the Corrosion Susceptibility of Metal-Matrix Composites. Corrosion 1988, 44, 680-684. [CrossRef]

28. Lekatou, A.G.; Gkikas, N.; Gousia, V.; Lentzaris, K.; Karantzalis, A.E. Effects of In Situ Intermetallics on the Microstructural Array and Saline Corrosion Performance of Cast Al/WCp Composites. J. Mater. Eng. Perform. 2018, 27, 5164-5176. [CrossRef]

29. Ananda Murthy, H.C.; Bheema Raju, V.; Shivakumara, C. Effect of TiN Particulate Reinforcement on Corrosive Behaviour of Aluminium 6061 Composites in Chloride Medium. Bull. Mater. Sci. 2013, 36, 1057-1066. [CrossRef]

30. Seah, K.H.W.; Krishna, M.; Vijayalakshmi, V.T.; Uchil, J. Corrosion Behaviour of Garnet Particulate Reinforced LM13 Al Alloy MMCs. Corros. Sci. 2002, 44, 917-925. [CrossRef]

31. Griffiths, A.J.; Turnbull, A. An investigation of the electrochemical polarization behaviour of 6061 aluminum metal matrix composites. Corros. Sci. 1994, 34, 23-35. [CrossRef]

32. Hu, J.; Chu, W.Y.; Fei, W.D.; Zhao, L.C. Effect of Interfacial Reaction on Corrosion Behavior of Alumina Borate Whisker Reinforced 6061Al Composite. Mater. Sci. Eng. A 2004, 374, 153-159. [CrossRef]

33. Kiourtsidis, G.E.; Skolianos, S.M. Corrosion Behavior of Squeeze-Cast Silicon Carbide-2024 Composites in Aerated 3.5 wt.\% Sodium Chloride. Mater. Sci. Eng. A 1998, 248, 165-172. [CrossRef]

34. Albiter, A.; Contreras, A.; Salazar, M.; Gonzalez-Rodriguez, J.G. Corrosion Behaviour of Aluminium Metal Matrix Composites Reinforced with TiC Processed by Pressureless Melt Infiltration. App. Electr. 2006, 36, 303-308. [CrossRef]

35. Kiourtsidis, G.E.; Skolianos, S.M. Pitting Corrosion of Artificially Aged T6 AA2024/SiCp Composites in 3.5 wt.\% NaCl Aqueous Solution. Corros. Sci. 2007, 49, 2711-2725. [CrossRef]

36. Alaneme, K.K.; Bodunrin, M.O. Corrosion Behavior of Alumina Reinforced Aluminum (6063) Metal Matrix Composites. J. Min. Mat. Char. Eng. 2011, 10, 1153-1165.

37. Yeh, J.W.; Chen, S.K.; Lin, S.J.; Gan, T.S.; Chin, T.S.; Shun, T.T. Nanostructured high entropy alloys with multiple principal elements: Novel alloy design concepts and outcomes. Adv. Eng. Mat. 2004, 6, 299-303. [CrossRef]

38. Yeh, J. Recent progress in high-entropy alloys. Ann. Chim. Sci. Mat. 2006, 31, 633-648. [CrossRef]

39. Karthik, G.M.; Panikar, S.; Janaki Ram, G.D.; Kottada, R.S. Additive manufacturing of an aluminum matrix composite reinforced with nanocrystalline high-entropy alloy particles. Mater. Sci. Eng. A 2017, 679, 193-203. [CrossRef]

40. Yang, X.; Dong, P.; Yan, Z.; Cheng, B.; Zhai, X.; Chen, H.; Zhang, H.; Wang, W. AlCoCrFeNi high-entropy alloy particle reinforced 5083Al matrix composites with fine grain structure fabricated by submerged friction stir processing. J. Alloy. Compd. 2020, 836, 155411. [CrossRef]

41. Liu, Y.; Chen, J.; Li, Z.; Wang, X.; Fan, X.; Liu, J. Formation of transition layer and its effect on mechanical properties of AlCoCrFeNi high-entropy alloy/Al composites. J. Alloy. Compd. 2019, 780, 558-564. [CrossRef]

42. Tan, Z.; Wang, L.; Xue, Y.; Zhang, P.; Cao, T.; Cheng, X. High entropy alloy particle reinforced Al-based amorphous alloy composite with ultrahigh strength prepared by spark plasma sintering. Mater. Des. 2016, 109, 219-226. [CrossRef]

43. Lu, T.; Scudino, S.; Chen, W.; Wang, P.; Li, D.; Mao, M.; Kang, L.; Liu, Y.; Fu, Z. The influence of nanocrystalline CoNiFeAl0.4Ti0.6Cr0.5 high-entropy alloy particles addition on microstructure and mechanical properties of SiCp/7075Al composites. Mater. Sci. Eng. A 2018, 726, 126-136. [CrossRef]

44. Li, Q.; Bao, X.; Zhao, S.; Zhu, Y.; Lan, Y.; Feng, X.; Zhang, Q. The Influence of AlFeNiCrCoTi High-Entropy Alloy on Microstructure, Mechanical Properties and Tribological Behaviors of Aluminum Matrix Composites. Int. J. Met. 2020, 14, 1-11. [CrossRef] 
45. Kumar, K.P.; Krishna, G.M.; Rao, J.B.; Bhargava, N. Fabrication and characterization of 2024 aluminium-High entropy alloy composites. J. Alloy Comp. 2015, 640, 421-427. [CrossRef]

46. Yuan, Z.; Tian, W.; Li, F.; Fu, Q.; Wang, X.; Qian, W.; An, W. Effect of heat treatment on the interface of high-entropy alloy particles reinforced aluminum matrix composites. J. Alloy. Comp. 2020, 822, 153658. [CrossRef]

47. Wang, N.; Wu, B.; Wu, W.; Li, J.; Ge, C.; Dong, Y.; Zhang, L.; Wang, Y. Microstructure and properties of aluminium-high entropy alloy composites fabricated by mechanical alloying and spark plasma sintering. Mater. Today Commun. 2020, 25, 101366. [CrossRef]

48. Senkov, O.N.; Wilks, G.B.; Miracle, D.B.; Chuang, C.P.; Liaw, P.K. Refractory high-entropy alloys. Intermetallics 2010, 18, 1758-1765. [CrossRef]

49. Senkov, O.N.; Wilks, G.B.; Scott, J.M.; Miracle, D.B. Mechanical properties of $\mathrm{Nb}_{25} \mathrm{Mo}_{25} \mathrm{Ta}_{25} \mathrm{~W}_{25}$ and $\mathrm{V}_{20} \mathrm{Nb}_{20} \mathrm{Mo}_{20} \mathrm{Ta}_{20} \mathrm{~W}_{20}$ refractory high entropy alloys. Intermetallics 2011, 19, 698-706. [CrossRef]

50. Poulia, A.; Georgatis, E.; Lekatou, A.; Karantzalis, A.E. Microstructure and wear behavior of a refractory high entropy alloy. Int. J. Refract. Met. Hard Mater. 2016, 57, 50-63. [CrossRef]

51. Poulia, A.; Georgatis, E.; Lekatou, A.; Karantzalis, A.E. Dry sliding wear response of MoTaWNbV high entropy alloy. Adv. Eng. Mater. 2017, 19, 1600535. [CrossRef]

52. Lekatou, A.; Sfikas, A.K.; Karantzalis, A.E.; Sioulas, D. Microstructure and corrosion performance of Al-32\% Co alloys. Corros. Sci. 2012, 63, 193-209. [CrossRef]

53. Lekatou, A.; Sfikas, A.K.; Petsa, C.; Karantzalis, A.E. Al-Co Alloys Prepared by Vacuum Arc Melting: Correlating Microstructure Evolution and Aqueous Corrosion Behavior with Co Content. Metals 2016, 6, 46. [CrossRef]

54. Lekatou, A.; Sfikas, A.K.; Karantzalis, A.E. The influence of the fabrication route on the microstructure and surface degradation properties of $\mathrm{Al}$ reinforced by $\mathrm{Al}_{9} \mathrm{Co}_{2}$. Mater. Chem. Phys. 2017, 200, 33-49. [CrossRef]

55. Poulia, A. Development and Characterization of Refractory High Entropy Alloys-Evaluation of Their Mechanical Properties and Surface Degradation Behavior. Ph.D. Thesis, University of Ioannina, Ioannina, Greece, 2018. 